\title{
Design and Investigation of SST/nc-Si:H/M (M = Ag, Au, Ni) and M/nc-Si:H/M Multifunctional Devices
}

\author{
A. F. Qasrawi, ${ }^{1,2}$ Salam M. Kmail, ${ }^{1}$ Samah F. Assaf, ${ }^{1}$ and Z. M. Saleh ${ }^{1}$ \\ ${ }^{1}$ Department of Physics, Arab-American University, 10932 Jenin, West Bank, Palestine \\ ${ }^{2}$ Group of Physics, Faculty of Engineering, Atilim University, 06836 Ankara, Turkey
}

Correspondence should be addressed to A. F. Qasrawi; aqasrawi@atilim.edu.tr

Received 15 April 2013; Revised 26 June 2013; Accepted 1 July 2013

Academic Editor: Armin Gerhard Aberle

Copyright (C) 2013 A. F. Qasrawi et al. This is an open access article distributed under the Creative Commons Attribution License, which permits unrestricted use, distribution, and reproduction in any medium, provided the original work is properly cited.

Hydrogenated nanocrystalline Silicon thin films prepared by the very high frequency chemical vapor deposition technique (VHFCVD) on stainless steel (SST) substrates are used to design Schottky point contact barriers for the purpose of solar energy conversion and passive electronic component applications. In this process, the contact performance between SST and $\mathrm{M}(\mathrm{M}=\mathrm{Ag}, \mathrm{Au}$, and Ni) and between $\mathrm{Ag}, \mathrm{Au}$, and $\mathrm{Ni}$ electrodes was characterized by means of current-voltage, capacitance-voltage, and light intensity dependence of short circuit $\left(I_{\mathrm{sc}}\right)$ current and open circuit voltage $\left(V_{\mathrm{oc}}\right)$ of the contacts. Particularly, the devices ideality factors, barrier heights were evaluated by the Schottky method and compared to the Cheung's. Best Schottky device performance with lowest ideality factor suitable for electronic applications was observed in the SST/nc-Si:H/Ag structure. This device reflects a $V_{\text {oc }}$ of $229 \mathrm{mV}$ with an $I_{\mathrm{sc}}$ of $1.6 \mathrm{~mA} / \mathrm{cm}^{2}$ under an illumination intensity of $\sim 40 \mathrm{klux}$. On the other hand, the highest $I_{\mathrm{sc}}$ being $9.0 \mathrm{~mA} / \mathrm{cm}^{2}$ and the $V_{\mathrm{oc}}$ of $53.1 \mathrm{mV}$ were observed for $\mathrm{Ni} / \mathrm{nc}-\mathrm{Si}: \mathrm{H} / \mathrm{Au}$ structure. As these voltages represent the maximum biasing voltage for some of the designed devices, the SST/nc-Si:H/M and M/nc-Si:H/M can be regarded as multifunctional self-energy that provided electronic devices suitable for active or passive applications.

\section{Introduction}

Nanoscale crystalline silicon particles embedded in amorphous silica, where the nanoscale particles play a main role, have attracted the interest of researchers due to their applicability in electronics as thin film transistors [1]. Hydrogenated nanocrystalline silicon (nc-Si:H) is reported to exhibit a promising application as a stable high-efficiency solar cells and as a panel displays [2-5].

The hydrogenated nanocrystalline silicon layers are known to be highly influenced by the type of substrate they grow on. They have been grown on GaAs wafer substrates [6]. Analysis on these films reflected nonuniform electric field distribution. A series of nc-Si:H films have also been deposited on glass substrates at different silicate concentrations and different substrate temperatures by using the traditional radio frequency plasma-enhanced chemical vapor deposition (RF-PECVD) technique with an excitation frequency of $13.56 \mathrm{MHz}$ [7]. These films which grow on glass substrate at low temperature were characterized by average grain size, crystalline nature, and dark electrical conductivity data obtained from the Raman and electrical conductivity spectroscopy, respectively. These parameters are reported to be highly influenced by the substrate conditions. A threshold substrate temperature was determined by silane concentration as it appears in their corresponding spectroscopy versus substrate temperature. In addition, the fabrication of the nc-Si:H(n)/c-Si(p) heterojunctions diode on the p-type c$\mathrm{Si}$ (100) wafer [4] by the vapor phase epitaxy at $1200^{\circ} \mathrm{C}$ which was studied by means of temperature- and biasdependent transport mechanisms indicated a transition from nontunneling- to tunneling-dominant transport as temperature is lowered from 350 to $20 \mathrm{~K}$. Furthermore, efficient coreshell transparent conductive oxide (TCO)/a-Si/Si nanowires (SiNWs) heterojunction solar cells were fabricated on SiNW arrays prepared by metal-assisted wet chemical etching of an n-type silicon wafer [8]. As an important improvement in these cells, no shunt current was detected and the maximum short-circuit current reached $27 \mathrm{~mA} / \mathrm{cm}^{2}$.

In addition to the substrate type effect, inclusive reports that concentrate on the effect of metallic contact type used with the nc-Si:H films are relatively rare. Some reports that 
discussed the role of aluminum and gold metals on the performance of the nc-Si:H films grown on glass substrate are recently reported [9-11]. Here in this work, we will focus on the gold, silver, and nickel metal effects as point contacts to nc:Si-H thin films grown on stainless steel substrate by the very high-frequency chemical vapor deposition technique. Particularly, the current voltage characteristics between combinations of these metals will be investigated in detail; some of these contacts solar cell parameters will also be reported.

\section{Experimental Details}

Device quality nc-Si:H samples of $1.5 \mu \mathrm{m}$ thick were provided by United Solar Ovonic LLC. The samples were grown using very high-frequency chemical vapor deposition (VHF-CVD) on stainless steel (SST) substrates at a substrate temperature of about $200^{\circ} \mathrm{C}$. The nanocrystalline phase was achieved by heavy hydrogen dilution during growth. The resulting material consists of a nanocrystalline phase impeded in an amorphous silicon matrix. The Raman spectroscopy which was carried out at the United Solar Ovonic laboratories was used to measure the crystallinity of the films. In accordance with the firm published report [10] in Raman spectroscopy process, a laser spot with a diameter of $1-2 \mu \mathrm{m}$ and a wavelength of $532 \mathrm{~nm}$ was irradiated on the samples, and Raman scattering from the sample was measured by a monochrometer. The Gaussian curve fitting method is used in these types of analysis. Raman spectroscopy measurements conducted on the samples reveal that the volume fraction of the crystalline phase was about $60-80 \%$ of the total volume. For the purpose of electronic and photovoltaic applications, the electrical contacts to the films were made of silver, gold, and nickel point contact paints at the top of the samples. Light intensity which was provided from halogen lamp was varied by changing the elevation of the light source above the sample, with the appropriate calibration. The short-circuit photocurrent was recorded at $300 \mathrm{~K}$. The electrical data was registered by using Keithley 485 picoammeter and PHWE voltage source. To guarantee the reliability of the contacts, the current voltage characteristics were recorded at several times and between different contact points; the data reading was very stable and easily readable. The capacitance frequency and voltage characterizations were registered using LRC meter and a $5 \mathrm{MHz}$ function generator.

\section{Results and Discussion}

Figure 1 displays the transmittance electron microscopy images for a cross-sectional area of the $\mathrm{Si} H \mathrm{H}$ films. The automated analysis of the images revealed a film thickness of $1.5 \mu \mathrm{m}$. In general, the film appears to contain grains of $6 \times 20 \mathrm{~nm}$. On the other hand, high-resolution top view images which are illustrated in Figure 2 clearly reflect the nanocrystalline phase existence being impeded in the amorphous silicon phase. Rough estimate of the volume ratio of these phases is about $60-80 \%$ of the total volume which is consistent with the Raman spectroscopy measurements $[10,11]$.
Figures 3(a) and 3(b) display the current (I)-voltage $(V)$ characteristic curves for the SST/nc-Si:H/M and for M/nc$\mathrm{Si}: \mathrm{H} / \mathrm{M}$ device structures, respectively. The $I-V$ curve of the $\mathrm{SST} / \mathrm{nc}-\mathrm{Si}: \mathrm{H} / \mathrm{Ag}$ device structure shows a large difference between the resulting forward and reverse currents when subjected to a forward and reverse voltage in the range of $\sim 0.0- \pm 1.4$ V. Figure 3(a) indicates that the forward current is at least $10^{5}$ order of magnitude larger than that of the reverse for an applied forward to reverse voltage biasing, while the $I-V$ curve of the SST/nc-Si:H/Au device structure shown in inset-1 of Figure 3(a) reflects typical Ohmic nonrectifying character with very high current at applied voltages in the $\mathrm{mV}$ range. The current-voltage characteristics curve of the SST/nc-Si:H/Ni device structure illustrated in Inset-2 displays a forward current growth of the order of $10^{-3}$ as the voltage is raised from 0 to $50 \mathrm{mV}$. The main observable difference between the Ag contacted and the Ni contacted devices lay in their ability to withstand applied voltage. In other words, as the figures indicate, the SST/nc-Si:H/Ag device can be subjected to a voltage of $\sim 12$ times compared to SST/nc-Si:H/Ni device. As a clarifying example, a forward current of $\sim 19 \mu \mathrm{A}$ is obtainable at $0.95 \mathrm{~V}$ for the Ag contacted and at $0.045 \mathrm{~V}$ for the $\mathrm{Ni}$-contacted devices.

Figure 3(b) reflects the $I-V$ curves for the M/nc-Si:H/M devices. These device structures are constructed along the surface of the sample. The distance between each two electrodes was $\sim 1 \mathrm{~mm}$. As the figure displays, the voltage application was possible between -8.0 and $8.0 \mathrm{~V}$. That possibly is due to the larger electrode separations. For an applied voltage of $8.0 \mathrm{~V}$, the forward to reverse current ratio is found to be $1.5 \times$ $10^{4}$ and $1.5 \times 10^{3}$ for Ag/nc-Si:H/Ni and for Ag/nc-Si:H/Au devices, respectively. For the Ni/nc-Si:H/Au structure the ratio is 1.1 at $1.0 \mathrm{~V}$. The later indicates an approximately Ohmic nature of contacts with very weak rectification. These weak rectifying contact structures are attributed to more than one reason. One of these low resistance symmetrical contacts to a semiconductor is obtained if the barrier height is small compared to $k T$ in which carriers can flow over the barrier in either direction without any impediment. Another reason is the introduction of large number of recombination centers at the metal semiconductor interface (due to surface damage during the growth process) [12]. For all devices which are designed on the surface of the nc-Si:H films, the barrier height values are most probably affected by the metal work function values which are 4.26, 5.10, and $5.15 \mathrm{eV}$ for $\mathrm{Ag}, \mathrm{Au}$, and $\mathrm{Ni}$ metals, respectively [13].

It is worth noting that the current registry was limited to $\sim 100 \mu \mathrm{A}$ to prevent device heating. For this reasons, the SST/nc-Si:H/Ni will not be subjected to further analysis due to the low basing of voltage as $\mathrm{q} V<3 k T$. Similarly, the devices which show very weak rectification $(\mathrm{Ni} / \mathrm{nc}-\mathrm{Si}: \mathrm{H} / \mathrm{Au})$ or no rectification (SST/nc-Si:H/Au) will not be included in the forthcoming analysis. These two devices indicate that the SST, Ni, and Au metals exhibit either a low rectifying or Ohmic nature of contact to the surface of nc-Si:H thin films. Thus, any connection between one of these metals and Ag point contact will establish Schottky device structure as was mentioned previously. Particularly, from all the reported 


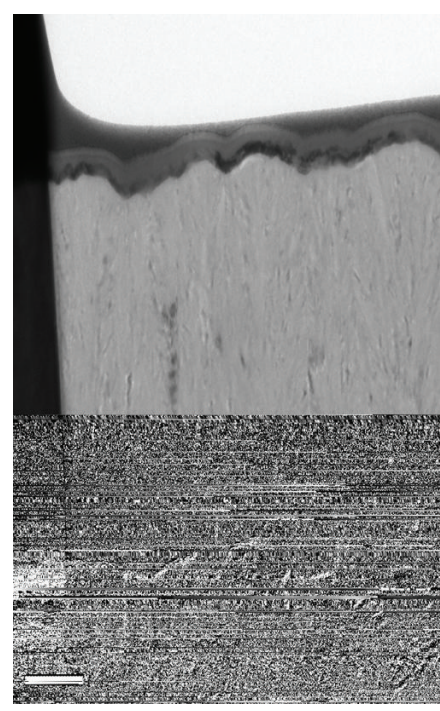

(a)

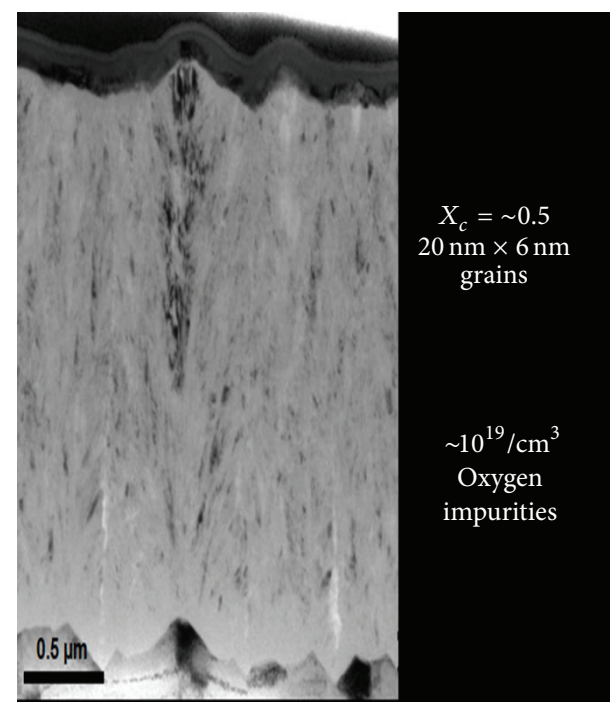

(b)

FIgURE 1: Shows a high-resolution TEM image of a cross-sectional view of the Si:H film.

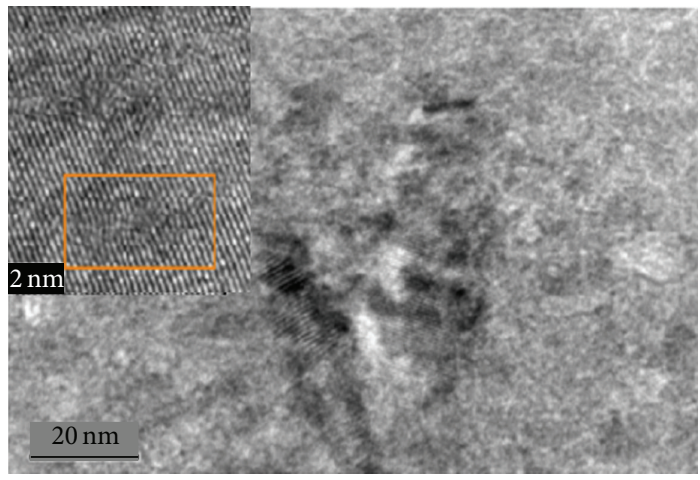

FIgURE 2: Top view high-resolution TEM images for nc-Si:H films.

devices only SST/nc-Si:H/Ag, Ag/nc-Si:H/Au, and Ag/nc$\mathrm{Si}: \mathrm{H} / \mathrm{Ni}$ will be subjected to Schottky device analysis.

The $I-V$ curves of the rectifying devices were analyzed in accordance with the thermionic emission of charged carriers through the barrier of the Schottky devices [14], the ideality factor $(n)$ and the device barrier height $\left(\phi_{b}\right)$ were evaluated from the plot of $\ln (I)-V$ for $\mathrm{q} V>3 k T$ (3kT: thermal energy) voltage range as shown in the typical illustrative example for the SST/nc-Si:H/Ag device in Figure 4(a). The calculations which were handled assuming a carrier effective mass of $0.35 m_{0}[4,5]$ revealed an ideality factor and barrier height of 2.37, 7.82, 7.50, and $0.85,0.84$, and $0.81 \mathrm{eV}$, for SST/nc$\mathrm{Si}: \mathrm{H} / \mathrm{Ag}, \mathrm{Ag} / \mathrm{nc}-\mathrm{Si}: \mathrm{H} / \mathrm{Au}$, and $\mathrm{Ag} / \mathrm{nc}-\mathrm{Si}: \mathrm{H} / \mathrm{Ni}$, respectively. The $\phi_{b}$ values are comparable to those reported in the literature [12]. The values of the ideality factor for all the devices are greater than one. This behavior could be attributed to many factors like device internal series resistance effect which cause particular voltage drop, the induced defects, Schottky barrier inhomogeneities, electron-hole pair recombination, and image force effects [15-18]. The series resistance effect is considered through the analysis using the method of Cheung to derive Cheung function $(H(I))$ [16-19] with the help of the plots presented in Figures 4(b) and 4(c). While the method presented by Figure 4(b) determines the ideality factor as 2.40, 6.51, and 4.24 for SST/nc-Si:H/Ag, Ag/nc-Si:H/Au, and $\mathrm{Ag} / \mathrm{nc}-\mathrm{Si}: \mathrm{H} / \mathrm{Ni}$ samples, the method of Cheung presented in Figure 4(c) allows the calculation of the barrier height as $0.83,0.88$, and $0.75 \mathrm{eV}$ with and average series resistance of 11.47, 778.1, and 1395.0, $(\mathrm{k} \Omega)$ for SST/nc-Si:H/Ag, Ag/nc$\mathrm{Si}: \mathrm{H} / \mathrm{Au}$, and $\mathrm{Ag} / \mathrm{nc}-\mathrm{Si}: \mathrm{H} / \mathrm{Ni}$, contacted devices, respectively. The later listed data indicates that there is no internal series resistance effect on the ideality factor and barrier height of the SST/nc-Si:H/Ag device; it has slight effect on the $n$ and $\phi_{b}$ of the $\mathrm{Ag} / \mathrm{nc}-\mathrm{Si}: \mathrm{H} / \mathrm{Au}$, and it significantly lowers the ideality factor from 7.50 to 4.26 for the $\mathrm{Ag} / \mathrm{nc}-\mathrm{Si}: \mathrm{H} / \mathrm{Ni}$ device. The effect of internal series resistance becomes more pronounced as the internal series resistance increases. The increase in the internal series resistance in the $\mathrm{Ag} / \mathrm{nc}-\mathrm{Si}: \mathrm{H} / \mathrm{Ni}$ device is mainly due to the $\mathrm{Ni}$ electrode separation being at $2.0 \mathrm{~mm}$ from the $\mathrm{Ag}$ as compared to the Au electrode which is at distance of $1.0 \mathrm{~mm}$.

The SST/nc-Si:H/Ag Schottky device was run on the passive device mode at an AC signal frequency of $100 \mathrm{~Hz}$. The resulting capacitance $(C)$-voltage curve is presented in Figure 5. As may be seen from the figure, the capacitance increases with increasing applied voltage till the voltage reaches $1.50 \mathrm{~V}$, where it then tends to remain constant. The data of the $C-V$ curve in the depletion region was analyzed in terms of the relation [12]

$$
\frac{1}{C^{2}}=\frac{2\left(V_{b i}+V_{a}-k T / q\right)}{q \varepsilon_{s} \varepsilon_{0} A^{2} N_{i}} .
$$

Here, $V_{b i}, \varepsilon_{s}$ and $N_{i}$ are the build in voltage, the static dielectric constant, and the concentration of the noncompensated ionized carriers, respectively. Plotting $1 / C^{2}$ versus $V_{a}$, as illustrated in the inset of Figure 5, substituting the values of $A$ as $4.0 \times 10^{-3} \mathrm{~cm}^{2}$ and $\varepsilon_{s}$ as 10.9 [4], and then 


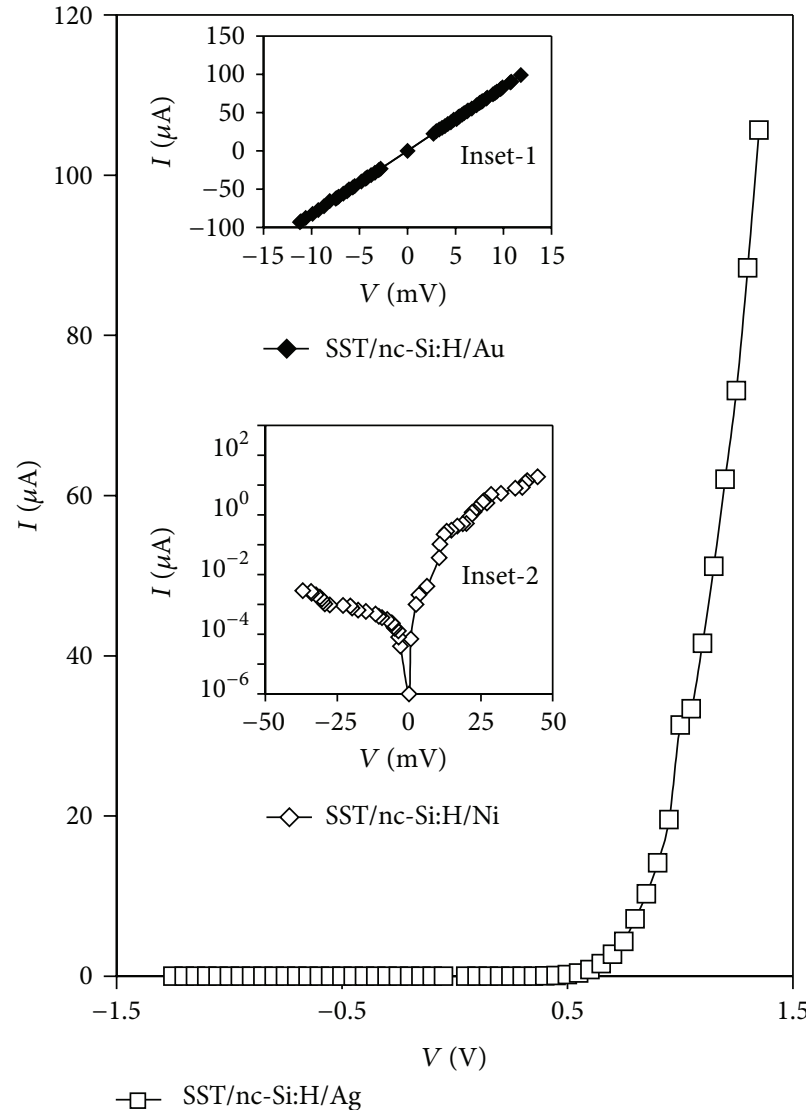

(a)

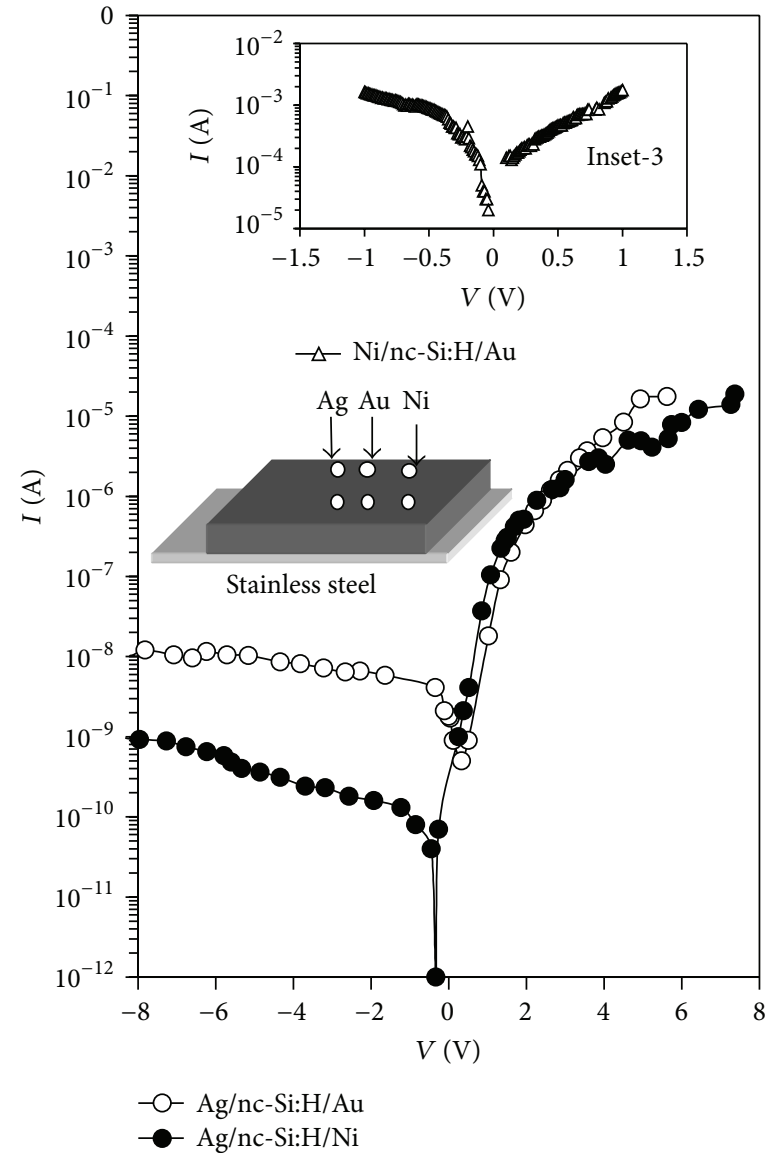

(b)

Figure 3: The $I-V$ curve for (a) SST/nc-Si:H/Ag, (b) Ag/nc-Si:H/Au, and Ag/nc-Si:H/Ni device structures. Inset-1, 2, and 3 represents the $I-V$ characteristics for SST/nc-Si:H/Au, SST/nc-Si:H/Ni, and Ni/nc-Si:H/Au diodes, respectively.

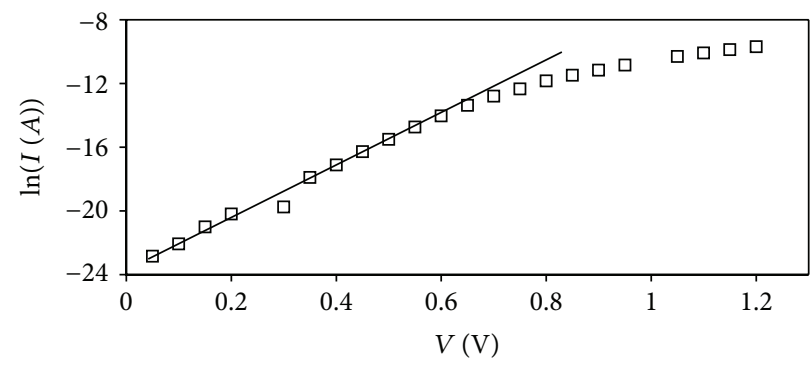

(a)

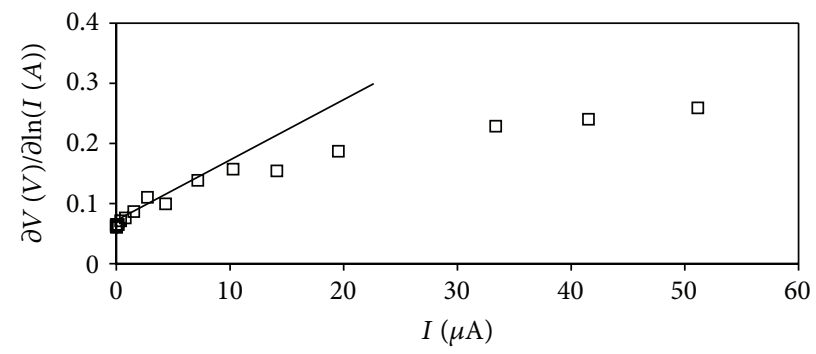

(b)

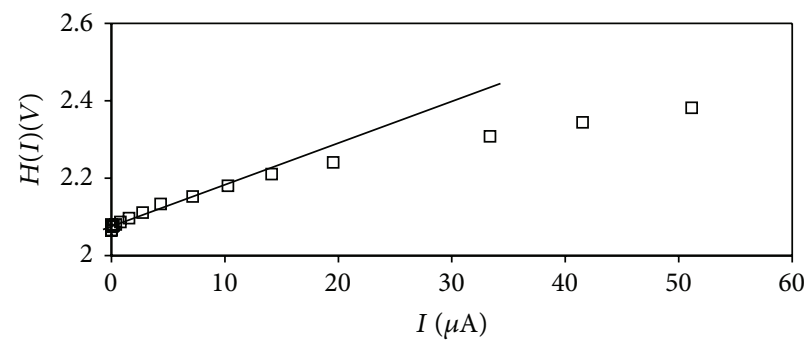

(c)

FIgURE 4: (a) The $\ln (I)-V$ characteristics for SST/nc-Si:H/Ag Schottky diodes. (b) The $\partial V / \partial \ln (I)-I$ curve for the same device. (c) The Cheung function current dependence. 


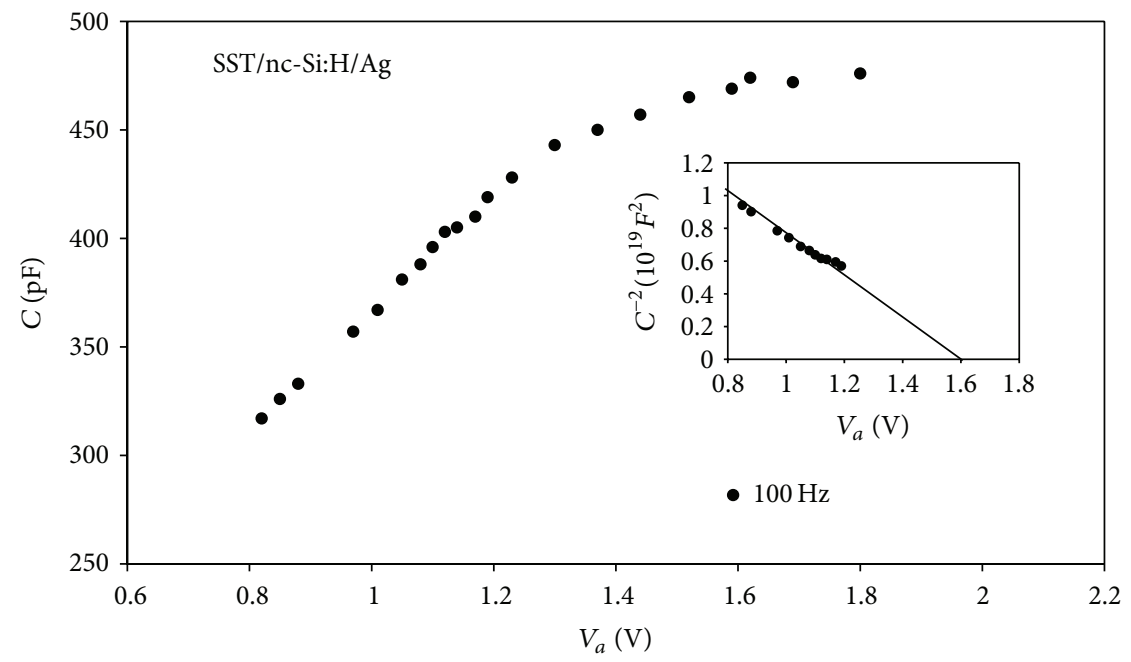

FIgURE 5: The capacitance-voltage characteristics for the SST/nc-Si:H/Ag at $100 \mathrm{~Hz}$. The inset represents the $\mathrm{C}^{-2}-\mathrm{V}$ dependence at $100 \mathrm{~Hz}$.

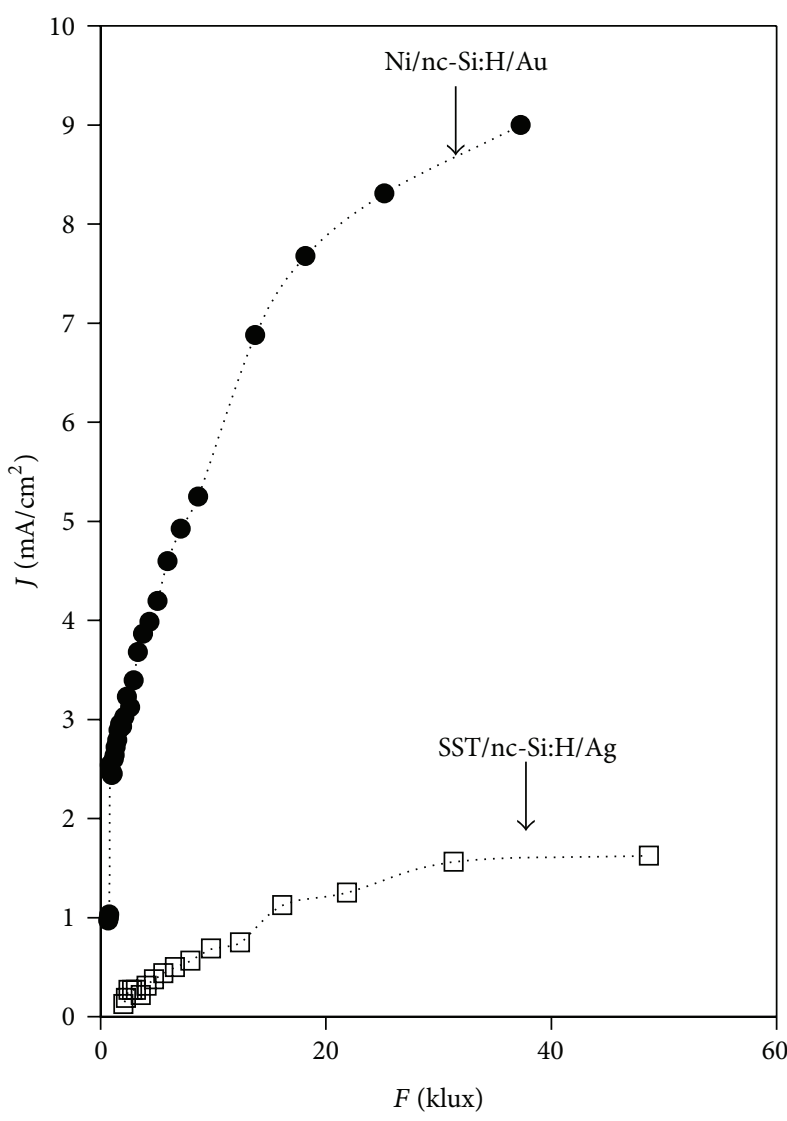

(a)

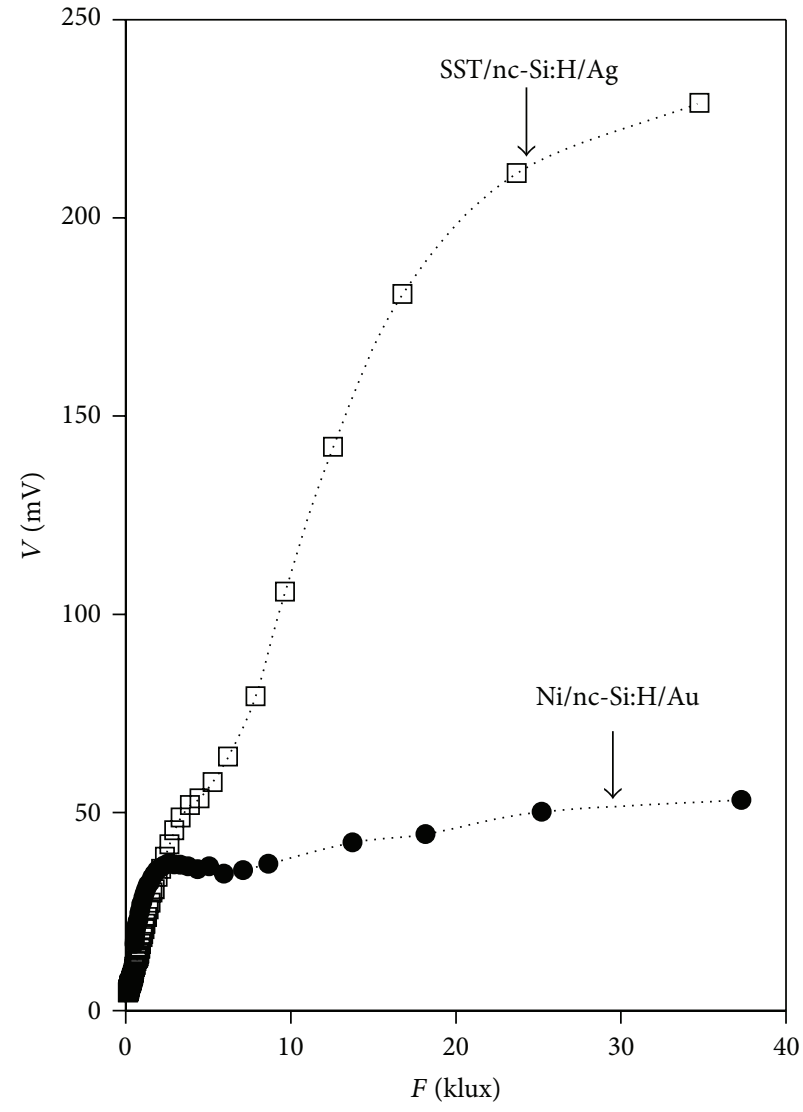

(b)

FIGURE 6: (a) and (b) reflects the short-circuit and open-circuit voltage-illumination intensity dependences, respectively, for SST/nc-Si:H/Ag and for $\mathrm{Ni} / \mathrm{nc}-\mathrm{Si}: \mathrm{H} / \mathrm{Au}$ device structures.

using the magnitudes of the slope and intercept of the solid line, the values of $V_{b i}$ and $N_{i}$ were determined as $6.6 \times$ $10^{16} \mathrm{~cm}^{-3}$ and $1.60 \mathrm{~V}$, respectively. These values appear to be higher than those reported for nc-Si:H as $1.2 \mathrm{~V}$. The difference in the values of the currently reported and published $V_{b i}$ values may be ascribed to the thickness of depletion layer, the applied signal frequency, sample inhomogeneities in addition to the interface charges that can contribute to a parasitic capacitance that acts in parallel with the depletion capacitance [4].

All the designed devices were subjected to halogen lamp light irradiation at illumination intensities $(F)$ in the range 
of $0.0-50 \mathrm{kLux}$. Among all the devices, only those which are named SST/nc-Si:H/Ag and Ni/nc-Si:H/Au are worth reporting as they exhibit remarkable smart characteristics. The other structures reveal a very low short-circuit current density $\left(J_{\text {sc }}\right)$ and low open-circuit voltage $\left(V_{\text {oc }}\right)$ response at maximum irradiation intensities. The relative data of $J_{\mathrm{sc}}-$ $F$ and the $V_{\text {oc }}-F$ dependencies for these two devices are shown in Figures 6(a) and 6(b). As appears in Figure 6, at an illumination intensity of $\sim 34$ klux, the maximum current density and maximum open-circuit voltage of the $\mathrm{Ni} / \mathrm{nc}$ $\mathrm{Si}: \mathrm{H} / \mathrm{Au}$ device are found to be $\sim 9.0 \mathrm{~mA} / \mathrm{cm}^{2}$ and $53.1 \mathrm{mV}$ and those of SST/nc-Si:H/Ag are $\sim 1.6 \mathrm{~mA} / \mathrm{cm}^{2}$ and $229 \mathrm{mV}$, respectively. The difference in these values is ascribed to the difference in carrier transport mechanism of these two types of configurations. Namely, in SST/nc-Si:H/M structure, the carriers move vertically between the two terminals. On the other hand, in M/nc-Si:H/M structure, the carriers mainly move laterally. Because of the nature of the oriented growth of the nc-Si:H film, the electrical properties are different in these two directions. This difference in current conduction highly affects performance of the devices. These values are close to the $J_{\mathrm{sc}}$ and $V_{\mathrm{oc}}$ values reported for $\mathrm{ZnO} / \mathrm{Cu}_{2} \mathrm{O} / \mathrm{Au}$ thin films as $3.89-4.18 \mathrm{~mA} / \mathrm{cm}^{2}$ and $240-160 \mathrm{mV}$ [20], respectively. Jia et al. have reported an improved values of $J_{\mathrm{sc}}=27 \mathrm{~mA} / \mathrm{cm}^{2}$ and $V_{\mathrm{oc}}=476 \mathrm{mV}$ of the nc-Si wires by constructing a TCO (transparent conductive oxide)/a-Si/Si nanowires (nw-Si) heterojunction solar cell. The device was designed on nwSi arrays prepared by metal-assisted wet chemical etching of an n-type silicon wafer. In this process, a stack of intrinsic and p-type amorphous-Si (a-Si) was deposited onto the nwSi arrays by plasma-enhanced chemical vapor deposition. On the top of the device, a $200 \mathrm{~nm}$ TCO layer was deposited on the a-Si layer by atomic layer deposition. This method of preparation resulted in no shunt current in the cells and resulted in these values of $J_{\mathrm{sc}}$ and $V_{\mathrm{oc}}[8]$ for a contact area of $7 \mathrm{~mm}^{2}$ which is larger than what we have used in this work $\left(0.04 \mathrm{~mm}^{2}\right)$. Furthermore, replacement of stainless steel with textured $\mathrm{Ag} / \mathrm{ZnO}$ for single junction $2 \mu \mathrm{m}$ thick nc-Si:H n-i$\mathrm{p}$ cells is reported to improve the $J_{\mathrm{sc}}$ from $15.2 \mathrm{~mA} / \mathrm{cm}^{2}$ for plain stainless steel to $23.4 \mathrm{~mA} / \mathrm{cm}^{2}$ [2].

For all studied samples, it is also evident from Figure 6(a) that $J$ is proportional to $F^{n}$. Generally, $n$ is observed to vary with intensity. Calculation of the values of $n$ in the studied intensity regions shows that it decreases from a value of $\sim 1.0$ at low and moderate intensities to a value of 0.24 at high intensities (above $18 \mathrm{klux}$ ). The observation of $n$ between 0.24 and 1.0 may be explained by considering the presence of exponential traps being distributed in the band gap of nc-Si:H films. The idea was originally proposed by Rose $[21,22]$. The exponential hole trap distribution is given as

$$
P_{t}=A \exp \left(-\frac{E_{t}-E_{v}}{k T^{*}}\right)
$$

where $A$ is the preexponential factor, $E_{t}-E_{v}$ represents the trap distribution location from the valence band edge, and $T^{*}$ is the characteristic temperature which can be adjusted to make the density of states vary more or less rapidly with energy. According to Rose, the exponent $n$ is given by

$$
n=\left(\frac{T^{*}}{T+T^{*}}\right)
$$

such that for $T^{*}=T, n \rightarrow 0.5 ; T^{*} \ll T, n \rightarrow 0$, and $T^{*} \gg T$, $n \rightarrow 1.0$. For $n \rightarrow 0.5$, the trap density is gathered close to the band-edge, corresponding to shallow states, whereas for $n \rightarrow 1.0$, the trap states extend close to the middle of the gap, corresponding to deep levels. As the light intensity is increased, more and more of the $P_{t}$ states are converted from trapping states to recombination states [22]. This conversion occurs as the Fermi-level penetrate through the $P_{t}$ states toward the valence band.

\section{Conclusions}

In this work, the current voltage and capacitance voltage characteristics of the SST/nc-Si:H/Ag Schottky diodes are investigated in detail. The relative illumination effect on this device is also studied. The other devices structure like SST/nc-Si:H/Au and SST/nc-Si:H/Ni and all the other M/ncSi:H/M combinations were also tested and evaluated. In all the tested devices, the ideality factor deviates from unity even after series resistance effect reduction. In general, the barrier height of these devices lies in the range of $0.85-$ $0.75 \mathrm{eV}$. The SST/nc-Si:H/Ag device can be biased from the solar energy arising from the Ni/nc-Si:H/Au structure, existing on the same surface of the film, as this device can provide a short-circuit current of $9 \mathrm{~mA} / \mathrm{cm}^{2}$. On the other hand, SST/nc-Si:H/Ag can be used as voltage provider for the $\mathrm{Ag} / \mathrm{nc}-\mathrm{Si}: \mathrm{H} / \mathrm{Ni}$ or $\mathrm{Ag} / \mathrm{nc}-\mathrm{Si}: \mathrm{H} / \mathrm{Au}$ Schottky diodes as it provides $\sim 0.23 \mathrm{~V}$ with low current input for passive device applications.

\section{References}

[1] I. C. Cheng, S. Allen, and S. Wagner, "Evolution of nanocrystalline silicon thin film transistor channel layers," Journal of Non-Crystalline Solids, vol. 338-340, no. 1, pp. 720-724, 2004.

[2] R. E. I. Schropp, H. Li, R. H. Franken et al., "Nanostructured thin films for multiband-gap silicon triple junction solar cells," Thin Solid Films, vol. 516, no. 20, pp. 6818-6823, 2008.

[3] H. Wagner, "Physical aspects and technological realization of amorphous silicon thin film solar cells," Physica Status Solidi B, vol. 192, pp. 229-239, 1995.

[4] J. J. Lu, J. Chen, Y. L. He, and W. Z. Shen, "Band offsets and transport mechanisms of hydrogenated nanocrystalline silicon/crystalline silicon heterojunction diode: key properties for device applications," Journal of Applied Physics, vol. 102, no. 6, Article ID 063701, 2007.

[5] X. Y. Chen, W. Z. Shen, H. Chen, R. Zhang, and Y. L. He, "High electron mobility in well ordered and lattice-strained hydrogenated nanocrystalline silicon," Nanotechnology, vol. 17, no. 2, pp. 595-599, 2006.

[6] C. S. Jiang, A. Ptak, B. Yan, H. R. Moutinho, J. V. Li, and M. M. Al-Jassim, "Microelectrical characterizations of junctions in solar cell devices by scanning Kelvin probe force microscopy," Ultramicroscopy, vol. 109, no. 8, pp. 952-957, 2009. 
[7] X. Y. Gao, J. T. Zhao, Y. U. F. Liu et al., "Characterized microstructure and electrical properties of hydrogenated nanocrystalline silicon films by raman and electrical conductivity spectra," Acta Physica Polonica A, vol. 115, no. 3, pp. 738-741, 2009.

[8] G. Jia, M. Steglich, I. Sill, and F. Falk, "Coreshell heterojunction solar cells on silicon nanowire arrays," Solar Energy Materials and Solar Cells, vol. 96, no. 1, pp. 226-230, 2012.

[9] K. W. Chan, B. T. Goh, S. Abdul Rahman, and Z. Aspanut, "Au/nc-Si:H core-shell nanostructures prepared by hot wire assisted plasma enhanced chemical vapor deposition technique," Surface Coating Technology, 2012.

[10] S. Guha and J. Yang, High-Efficiency Amorphous Silicon and Nanocrystalline Silicon-Based Solar Cells and Modules, United Solar Ovonic LLC, 2008.

[11] M. Meaudre, R. Meaudre, S. Vignoli, and O. Marty, "Density of states in hydrogenated microcrystalline silicon determined by space charge limited currents," Journal of Non-Crystalline Solids, vol. 299-302, no. 1, pp. 626-631, 2002.

[12] M. S. Tyagi, Introduction to Semiconductor Materials and Devices, John Wiley \& Sons, New York, NY, USA, 1988.

[13] Z. C. Feng, SiC Power Materials: Devices and Applications, Springer, Berlin, Germany, 2004.

[14] A. F. Qasrawi, F. G. Aljammal, N. M. Taleb, and N. M. Gasanly, "Design and characterization of TlInSe2 varactor devices," Physica B, vol. 406, no. 14, pp. 2740-2744, 2011.

[15] A. F. Qasrawi and N. M. Gasanly, "Investigation of the electrical parameters of Ag/p-TlGaSeS/C Schottky contacts," Materials Science and Engineering B, vol. 177, pp. 981-985, 2012.

[16] S. K. Cheung and N. W. Cheung, "Extraction of Schottky diode parameters from forward current-voltage characteristics," Applied Physics Letters, vol. 49, no. 2, pp. 85-87, 1986.

[17] G. Çankaya and B. Abay, "Current- and capacitance-voltage characteristics of $\mathrm{Cd} / \mathrm{p}$-GaTe Schottky barrier diodes under hydrostatic pressure," Semiconductor Science and Technology, vol. 21, no. 2, pp. 124-130, 2006.

[18] S. M. Sze, Physics of Semiconductor Devices, Wiley, New York, NY, USA, 1981.

[19] A. F. Qasrawi, S. M. S. Elayyat, and N. M. Gasanly, "Dynamical and passive characteristics of the Ag/TlGaSeS/Ag RFresonators," Crystal Research and Technology, vol. 47, pp. 615-619, 2012.

[20] T. Gershon, K. P. Musselman, A. Marin, R. H. Friend, and J. L. MacManus-Driscoll, "Thin-film $\mathrm{ZnO} / \mathrm{Cu} 2 \mathrm{O}$ solar cells incorporating an organic buffer layer," Solar Energy Materials and Solar Cells, vol. 96, no. 1, pp. 148-154, 2012.

[21] A. Rose, Concepts in Photoconductivity and Allied Problems, Interscience Publishers, New York, NY, USA, 1963.

[22] M. Misra and T. D. Moustakas, "Photoconductivity recombination kinetics in GaN films," in Proceedings of the Materials Research Society Symposium, vol. 622, pp. T541-T546, April 2000. 

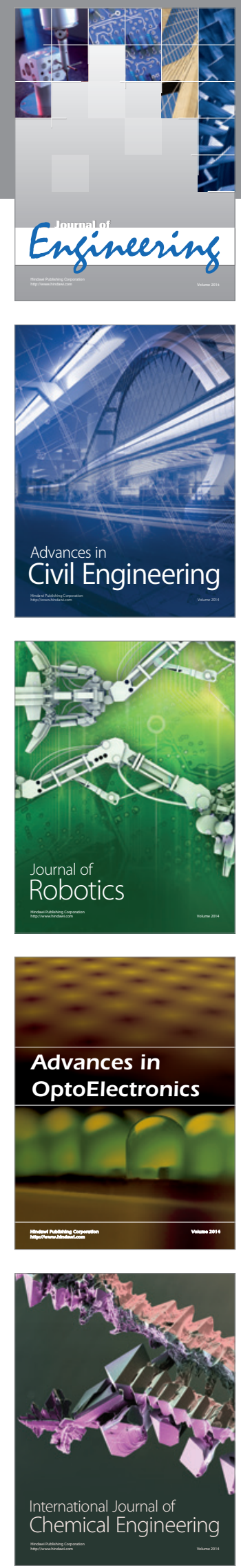

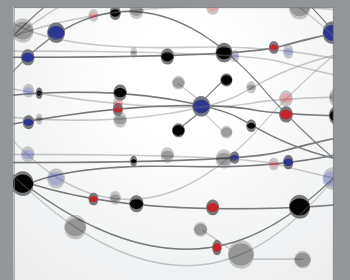

The Scientific World Journal
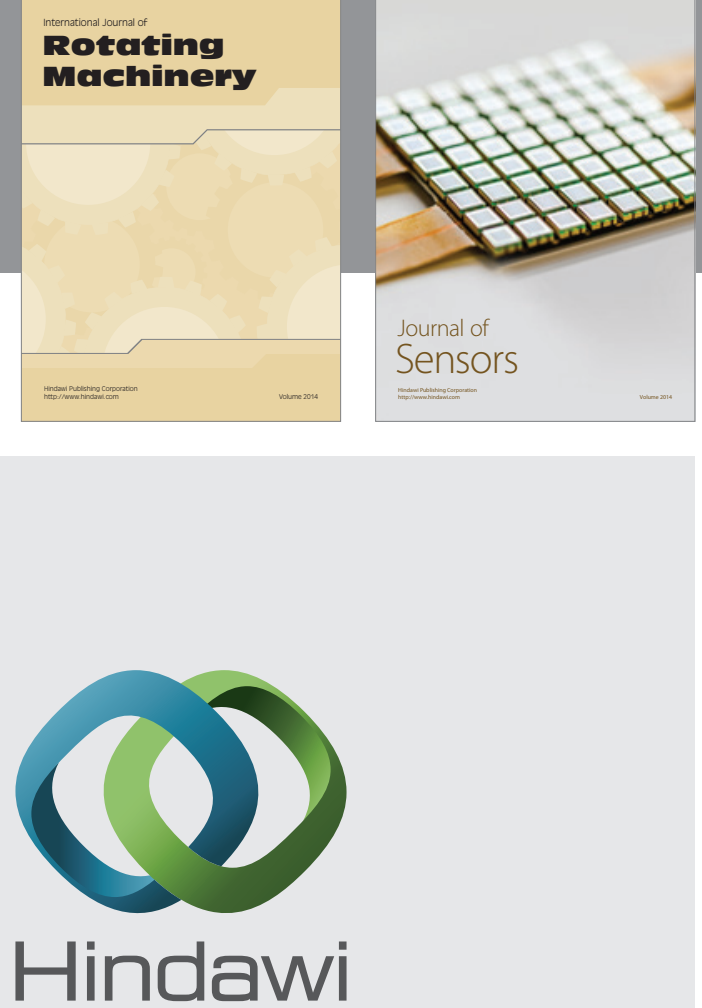

Submit your manuscripts at http://www.hindawi.com
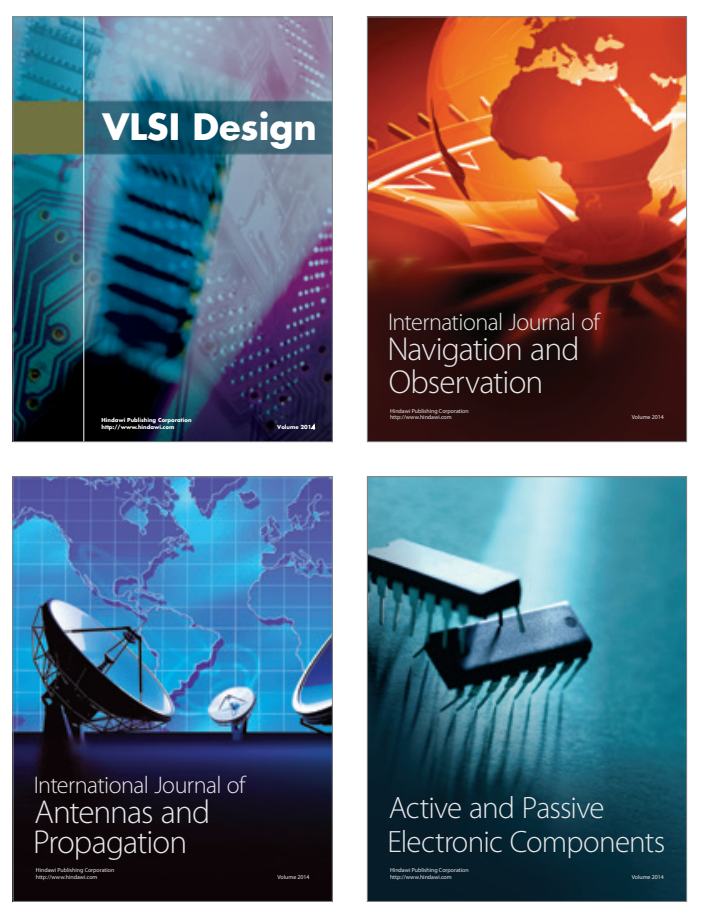
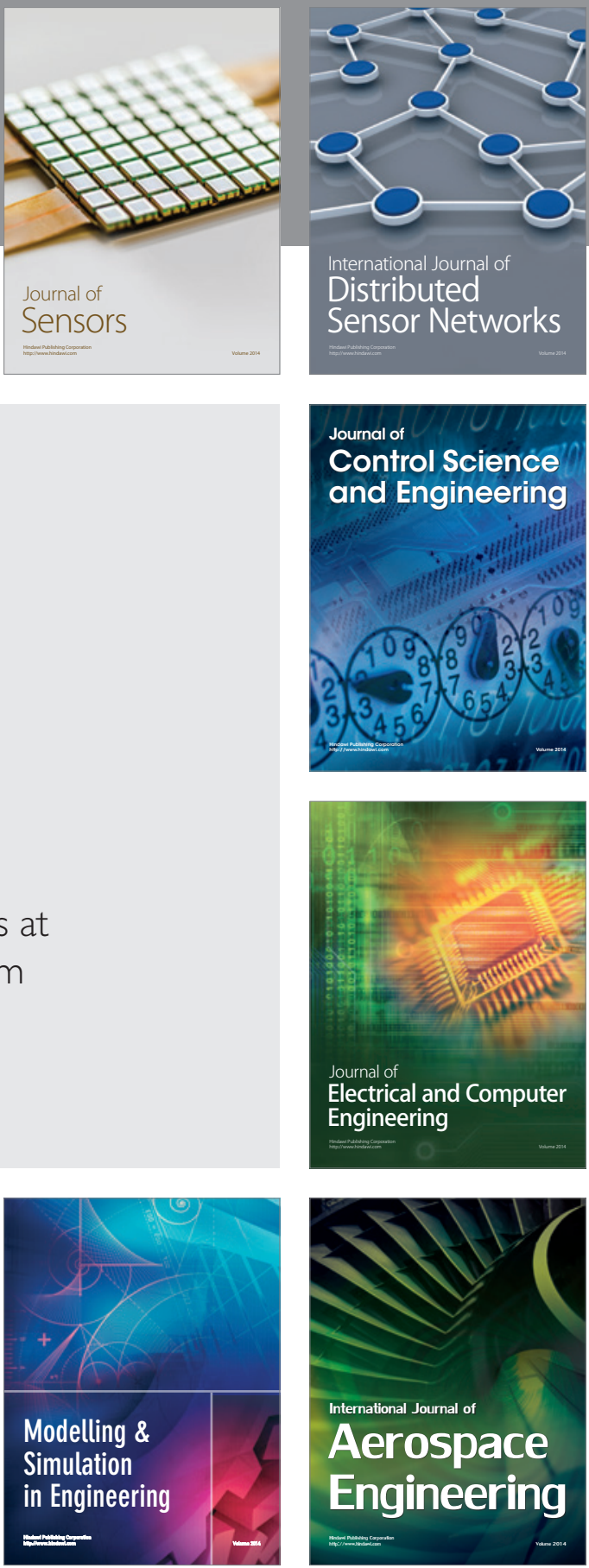

Journal of

Control Science

and Engineering
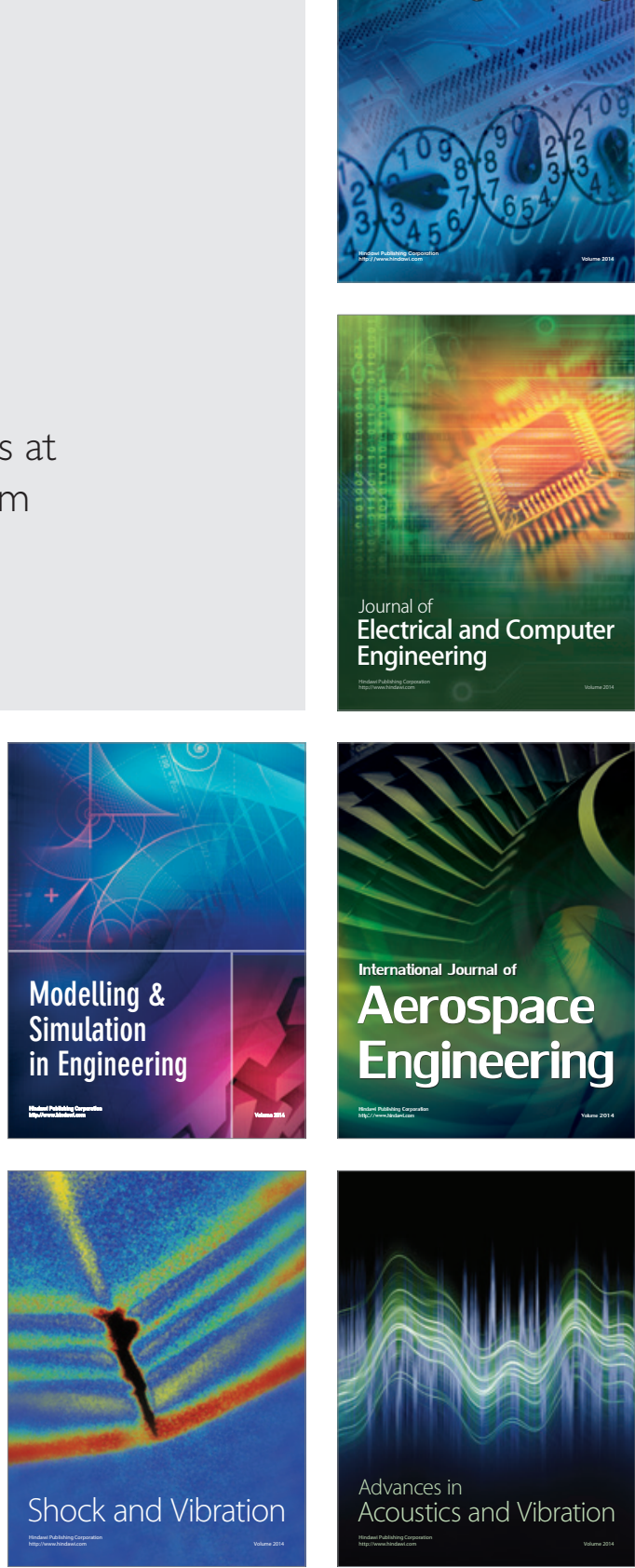